Article

\title{
Synthesis and Thermomechanical Properties of Polyurethanes and Biocomposites Derived from Macauba Oil and Coconut Husk Fibers
}

\section{Rafael L. Quirino ${ }^{1, *}$, Taynara F. da Silva ${ }^{2}$, Amanda Payne ${ }^{1}$, Roseany de V. V. Lopes ${ }^{3}$, Leonardo G. Paterno ${ }^{2}$ and Maria José A. Sales ${ }^{2}$}

1 Chemistry Department, Georgia Southern University, Statesboro, GA 30458, USA; E-Mail: am02837@georgiasouthern.edu

2 Laboratório de Pesquisa em Polímeros, Instituto de Química, Universidade de Brasília, Brasília, DF, 70910-000, Brazil; E-Mails: taynarafersil@gmail.com (T.F.S.); leonardopaterno@hotmail.com (L.G.P.); mazesales@gmail.com (M.J.A.S.)

3 Faculdade do Gama, Universidade de Brasília, Gama, DF, 72429-005, Brazil; E-Mail: roseanyvieira@yahoo.com.br

* Author to whom correspondence should be addressed; E-Mail: rquirino@georgiasouthern.edu. Academic Editor: Philippe Dubois

Received: 30 July 2015 / Accepted: 20 August 2015 / Published: 26 August 2015

\begin{abstract}
This work reports on a very effective route to produce bio-based polyurethanes (PUs) and composites with high content of renewable carbon sources. The PUs are prepared with polyols synthesized from macauba oil (Acrocomia aculeata) and methylene diphenyl diisocyanate, at different $[\mathrm{NCO}] /[\mathrm{OH}]$ molar ratios. Later, biocomposites are prepared with the as-obtained PUs reinforced with coconut husk fibers. The successful synthesis of natural oil-based polyols is ascribed to the hydroxylation and consumption of carbon-carbon double bonds in the fatty acid chains of the original starting oil as attested by FTIR spectroscopy. According to different thermal analysis techniques (TG, DTG, and DTA), the increase in the $[\mathrm{NCO}] /[\mathrm{OH}]$ molar ratio improves the thermal stability of PUs, likely due to an increase of crosslinks. Dynamic mechanical analysis evidences the reinforcement effect of coconut husk fibers in bio-based PUs. The present PUs and composites are of low-cost and environmentally friendly materials for structural applications.
\end{abstract}

Keywords: bio-based composites; polyurethanes; macauba oil; coconut husk fibers 


\section{Introduction}

The use of raw materials from renewable resources, such as vegetable oils and natural fibers, for the manufacturing of biocomposites has increased at a tremendous rate. The main goal of such an approach is to reduce the environmental footprint left by petroleum-based thermoplastic resins and inorganic engineered fibers. Moreover, the abundance and low cost of renewable raw materials have also positively contributed for the development of biocomposites [1-5]. In particular, the substitution of petroleum-based polyols to natural oil-based polyols to produce polyurethanes (PUs) has gained special attention [6]. PUs are currently very prominent materials due to their wide range of applications and properties, which depend on their synthesis process [1-4]. Additionally, composites made from PUs exhibit good mechanical and thermal properties, thereby increasing their versatility [5,7].

Vegetable oils are abundantly available, inexpensive, and highly-functional materials. They are composed of triglycerides containing 14-18 carbon-long fatty acid chains, which may have up to three carbon-carbon double bonds [1,3-5]. The most common unsaturated fatty acids found in vegetable oils are linoleic, and linolenic acids [1,3-5]. The scientific literature reports on the preparation of polymers from soybean, linseed, sunflower, palm, cotton, and castor oils through synthetic pathways that involve reactions, such as epoxidation, transesterification, or acrylation [1,5]. The possible reactions of a vegetable oil are tightly related to its functional groups, present in the triglyceride unit, which may include carbon-carbon double bonds, ester groups, allylic carbons, and carbonyl groups [3,5]. Additionally, straight chain polymerization, many of these groups can lead to crosslinking of the fatty acids present in the oil [1].

The unsaturated fatty acid chains can be easily epoxidized [1-4] with an organic acid in the presence of hydrogen peroxide $[1,3,8]$. The ring-opening of oxyrane rings gives rise to polyols $[1-4,8]$. The polyols, along with isocyanates, are the main "ingredients" for the preparation of PUs via polycondensation $[5,8]$. In addition to the chemical structure of the co-monomers, the reaction stoichiometry and morphological aspects, such as degree of crystalinity, as shown for segmented thermoplastic PU elastomers [9-13], also plays an important role in the final properties of PU materials. Indeed, it has been recently shown that the molar ratio $[\mathrm{NCO}] /[\mathrm{OH}]$ is directly related to the crosslink density of jathropa oil methyl ester-based PUs [14]. It is therefore hypothesized that thermal and mechanical properties of PUs fabricated from oils with a different fatty acid composition than jathropa oil are also related to the $[\mathrm{NCO}] /[\mathrm{OH}]$ molar ratio employed in the synthesis, and that differences in crosslink density will translate into differences in thermo-mechanical properties. These relationships are verified herein.

The present contribution is aimed at providing a simple and yet very efficient route for the preparation of bio-based PUs and composites with high content of renewable carbon sources. It describes the synthesis of polyols from macauba oil (MO) and their use in the preparation of bio-based PUs. The bio-based PUs are prepared with different methylene diphenyl diisocyanate (MDI) to polyol molar ratios, or else $[\mathrm{NCO}] /[\mathrm{OH}]$, in order to establish its effect on the PU's thermal and mechanical properties. Macauba (Acrocomia aculeata) is a common palm tree found in tropical regions. Its fruit has a high oil content that serves several purposes, such as animal and human feeding, soap precursors, and coatings. The composition of unsaturated fatty acids in macauba oil (MO) is $40 \%-58 \%$ of oleic acid, $3 \%-18 \%$ of linoleic acid, and $2 \%$ of linolenic acid $[15,16]$. Due to its high unsaturated fatty acid content, MO is a suitable starting material for the preparation of bio-based PUs. Its unique fatty acid composition suggests 
that PUs prepared from MO exhibit distinct properties when compared to systems prepared from other vegetable oils. It, therefore, becomes relevant to investigate and establish the thermo-mechanical properties of MO-based PUs, and their relationship with different $[\mathrm{NCO}] /[\mathrm{OH}]$ molar ratios. Indeed, it is expected that with a different degree of unsaturation in comparison to other oils, the MO-based PUs prepared in this work exhibit distinct crosslink densities and thermo-mechanical properties than previously observed with other oils. The proposition of $\mathrm{MO}$ as a new bio-renewable building block for PUs requires a careful investigation of the relationships between the $[\mathrm{NCO}] /[\mathrm{OH}]$ molar ratios employed during the synthesis and the final properties obtained for these new materials.

Since only few low-cost applications are currently being sought for this abundant and underused oil, it is believed that the use of MO in polymeric systems hasn't reached its full potential yet, making it an ideal candidate for being studied as a possible precursor in the preparation of bio-based PUs and composites. Additionally, it is reported the preparation of biocomposites with bio-based PUs reinforced with coconut husk fibers. Coconut husk fibers are extracted from the seed of the coconut palm (Cocos nucifera), and its predominant composition is $37-44 \mathrm{wt} \%$ of cellulose, $33 \mathrm{wt} \%$ of lignin, and $12-20 \mathrm{wt} \%$ of hemicellulose, which may vary according to the seasonal conditions, age, and variety of the plant $[6,17-19]$. Coconut husk fibers are inexpensive agricultural and agro-industrial residues and their use in such composites can significantly reduce their environmental impact $[6,17]$. The use of coconut husk fibers as reinforcement in MO-based PU composites constitutes a potential alternative to more costly systems prepared with bio-based PUs recently investigated, such as soy polyol-based PUs [20] and castor oil hyperbranched PUs reinforced with graphene [21].

It is important to point out that the fibers were used in natura, without the addition of any compatibilizer in the composites formulations. Although these strategies could aid in the mixing of components and further improve the matrix-filler interface, they may not play a role in some systems. For example, as reported by Castro et al. [22], the use of castor oil as a compatibilizer for the preparation of nanocomposites of green polyethylene and cellulose nano-crystals has no influence over the storage modulus and $\tan \delta$. Moreover, as it has been pointed out by Mazzon et al. [23] that biomass-derived epoxy foams can be designed with specific properties, such as $T_{\mathrm{g}}$, stiffness, density, and morphology, provided that the cure obeys rigorous equilibrium rules. In this sense, the approach reported herein is less restrictive than others but still shows great potential for improvements.

All materials prepared herein are characterized by Fourier-transform infrared spectroscopy (FTIR), thermogravimetry (TG), derivative thermogravimetry (DTG), differential thermal analysis (DTA), dynamic mechanical analysis (DMA), and scanning electron microscopy (SEM). The role of $[\mathrm{NCO} /[\mathrm{OH}]$ molar ratio in the thermo-mechanical properties of bio-based PUs and composites is thoroughly investigated. The influence of fiber-matrix interactions in the composites' end properties is also explored.

\section{Experimental}

\subsection{Materials}

The MO was purchased from Cocal Brasil ${ }^{\mathrm{TM}}$ (Abaeté-MG, Brazil) while coconut husk fibers were provided by the Pilot Unit Beneficiation of Green Coconut Bark from Embrapa Agroindústria Tropical (Fortaleza-CE, Brazil). Formic acid (Isofar Brazil, 85\%) and 30 vol.\% aqueous solution of hydrogen 
peroxide (Dinâmica ${ }^{\mathrm{TM}}$, Diadema-SP, Brazil) were used as received. Analytical grades of MDI, sodium bisulfite, sodium bicarbonate, diethyl ether, sodium carbonate, anhydrous sodium sulfate, pyridine, acetic anhydride, $n$-butanol, methanol (99.8\%), phenolphthalein, potassium hydroxide, bromocresol green, dibutylamine, toluene, hydrochloric acid (37\%), isopropyl alcohol, and sulfuric acid (95\%-97\%) were all purchased from Sigma-Aldrich Vetec ${ }^{\mathrm{TM}}$, Duque de Caxias-RJ, Brazil and used without additional purification. 3A molecular sieves were purchased from Aldrich Co. (St. Louis, MO, USA). Methylene chloride was procured from Fisher Scientific (Pittsburgh, PA, USA).

\subsection{Methods}

\subsubsection{Polyol Synthesis}

Polyols from MO (PMO) were synthesized following the procedure described in the literature [24] with some modifications. $25 \mathrm{~g}$ (corresponding to $3.13 \mathrm{mmol}$ of carbon-carbon double bonds) of degummed $\mathrm{MO}$ were mixed with $22 \mathrm{~mL}$ of formic acid. Then, $24 \mathrm{~mL}$ of $\mathrm{H}_{2} \mathrm{O}_{2}$ were slowly added to the mixture, at room temperature, over the course of $30 \mathrm{~min}$, under strong mechanical stirring. After addition of $\mathrm{H}_{2} \mathrm{O}_{2}$, the mixture was heated to $65^{\circ} \mathrm{C}$ for $5 \mathrm{~h}$. Then, heating was stopped and $10 \%(\mathrm{w} / \mathrm{v})$ sodium bisulfate solution was added. The organic layer was isolated and washed with $10 \%(\mathrm{w} / \mathrm{v})$ sodium carbonate solution until complete acid neutralization. Sodium sulfate was used to absorb the residual water, and the products were finally dried in a rotary evaporator.

\subsubsection{Preparation of PUs}

In order to prepare the PUs, the hydroxyl index of the polyols $\left(15.20 \mathrm{mg} \mathrm{KOH} \cdot \mathrm{g}^{-1}\right)$ was previously determined by titration according to ASTM D 1957-86 [25]. The free isocyanate (-NCO) content present in the MDI (30.82\%) was also determined by titration according to ASTM D 5155-96 [26]. After determining the functionality of the polyol and diisocyanate, the PUs were prepared in glass vessels by mixing the polyol with the appropriate amount of MDI required in order to obtain $[\mathrm{NCO}] /[\mathrm{OH}]$ molar ratios of $11.3,13.6$, and 15.1 . The mixtures were mechanically stirred under $3000 \mathrm{rpm}$ for $1 \mathrm{~min}$ and then poured into Teflon ${ }^{\mathrm{TM}}$ molds. The molds were placed in a regular oven and kept at $100{ }^{\circ} \mathrm{C}$ for $24 \mathrm{~h}$. The PU samples were named, respectively, PUMO-11.3, PUMO-13.6, and PUMO-15.2 where the numbers stand for the $[\mathrm{NCO}] /[\mathrm{OH}]$ molar ratio used in PU preparation. Due to the low hydroxyl index of the starting $\mathrm{MO},[\mathrm{NCO}] /[\mathrm{OH}]$ molar ratios lower than 11.3 did not produce a polymeric matrix.

\subsubsection{Composites Preparation}

In an attempt of improving the mechanical properties of the weakest PUs, coconut husk fiber composites were prepared exclusively from PMO produced at a $[\mathrm{NCO}] /[\mathrm{OH}]$ molar ratio of 11.3. The coconut husk fibers in natura (untreated), with approximately $4.6 \mathrm{wt} \%$ of humidity, used for the preparation of the composites were ground using a blender and sieved to obtain particles with diameters $\leq 74 \mu \mathrm{m}$. After stirring the PU reaction mixture for $5 \mathrm{~min}$, the ground fibers were added to the reaction vessel and the system was kept under agitation for $2 \mathrm{~min}$ at $3000 \mathrm{rpm}$. The resulting mixtures were submitted to the same cure conditions adopted for the PUs. Composites were prepared with $10 \mathrm{wt} \%$ and 
$20 \mathrm{wt} \%$ coconut husk fibers and named, respectively PUMO-11.3-10, PUMO-11.3-20, PUBIMO-11.3-10, and PUBIMO-11.3-20, where the number after the name of the PU corresponds to the wt $\%$ of fibers used.

\subsection{Materials Characterizations}

All FTIR spectra were obtained on a Nicolet 6700 spectrometer (Thermo Scientific, Waltham, MA, USA) in the $400-4000 \mathrm{~cm}^{-1}$ spectral region, with $128 \mathrm{scans}$, and $4 \mathrm{~cm}^{-1}$ resolution. FTIR transmittance measurements were performed on liquid samples. An attenuated total reflectance (ATR) accessory, with ZnSe crystal (Pike Technologies, Fitchburg, WI, USA), was used for the analysis of PUs and composites.

TG and DTG were performed with a thermobalance Shimadzu DTG-60H (Kyoto, Japan). TG/DTG curves of PUs and composites were carried out under $\mathrm{N}_{2}$ atmosphere $\left(30 \mathrm{~mL} \cdot \mathrm{min}^{-1}\right)$ using a Pt pan. For all samples, the mass used was approximately $7 \mathrm{mg}$, and a heating rate of $10^{\circ} \mathrm{C} \cdot \mathrm{min}^{-1}$ was employed in a temperature interval from 25 to $700{ }^{\circ} \mathrm{C}$. These experiments were carried out in triplicate. The decomposition temperature $\left(T_{\mathrm{d}}\right)$ was determined by DTG and the heat of exothermic and endothermic processes was determined by DTA.

The storage modulus $\left(E^{\prime}\right)$ and glass transition temperatures $\left(T_{\mathrm{g}}\right)$ of all samples were assessed by dynamic mechanical analysis using a DMA Q800 equipment (TA Instruments, New Castle, DE, USA) operating in the tensile mode. The DMA Multi-Frequency-Strain experiments were carried out on rectangular specimens $(17.50 \mathrm{~mm} \times 15.0 \mathrm{~mm} \times 2.90-1.250 \mathrm{~mm}$, length $\times$ width $\times$ thickness, respectively) obtained from the PU and composite samples. A frequency of $1 \mathrm{~Hz}$ and amplitude of 14.0 $\mu \mathrm{m}$ were employed over a $-60-200{ }^{\circ} \mathrm{C}$ temperature range, with a heating rate of $3{ }^{\circ} \mathrm{C} \cdot \mathrm{min}^{-1}$. $T_{\mathrm{g}}$ was determined from the peak of the $\tan \delta$ curves. The experiments were repeated to ensure consistency and the data reported reflects the average of the values obtained within a $10 \%$ error.

$1 \mathrm{~g}$ of each PU prepared from MO was submitted to Soxhlet extraction for $24 \mathrm{~h}$ with methylene chloride. The solvent was removed from the extracts using a rotary evaporator. Soluble and insoluble materials were dried in a vacuum oven at $70{ }^{\circ} \mathrm{C}$ overnight before final weighing and determination of extractable percentage.

For the scanning electron microscopy (SEM) analysis, samples were previously immersed in liquid nitrogen for $2 \mathrm{~min}$ and then mechanically fractured. The resulting specimens were then attached to the metallic stub and coated with gold to limit charging effects during the analysis. The micrographs were acquired with a JEOL JSM-7600F field emission scanning electron microscope (Peabody, MA, USA). The microscope was operated at $1.00 \mathrm{kV}$ accelerating voltage, and at working distances varying from 13.0 to $17.0 \mathrm{~mm}$.

\section{Results and Discussion}

The use of vegetable oils for the synthesis of polymeric materials has significantly increased since 2000 . The polymerization of various unsaturated oils can be achieved by taking advantage of carbon-carbon double bonds in the oils' chemical structure through various processes. With $39 \%$ of its fatty acid chains being oleic acid, and 5\% being linoleic acid [27], the chemical structure of MO shows potential for polymerization through the preliminary preparation of polyols and their subsequent polycondensation with diisocyanates for the synthesis of bio-based PUs. 
The FTIR spectrum of MO (Figure 1) exhibits characteristic peaks corresponding to $\mathrm{C}=\mathrm{C}-\mathrm{H}$ vibrations at $1650 \mathrm{~cm}^{-1}$ and $3010 \mathrm{~cm}^{-1}$, as well as peaks related to $\mathrm{C}-\mathrm{H}$ symmetric and asymmetric stretching of aliphatic chains $\left(2924 \mathrm{~cm}^{-1}, 2850 \mathrm{~cm}^{-1}\right.$, respectively), and $\mathrm{C}=\mathrm{O}$ stretch deformation at approximately $1746 \mathrm{~cm}^{-1}$ [28-30]. On the FTIR spectrum of BIMO, the product of the transesterification of MO with methanol, a change on the profile of the peaks in the $1000-1400 \mathrm{~cm}^{-1}$ range can be observed, along with the appearance of a typical ester band at $1035 \mathrm{~cm}^{-1}$ (Figure 1) [31,32]. These differences between the FTIR spectra of MO and BIMO suggest that the methanolysis reaction was successful. The polyol formation for both MO and BIMO (PMO and PBIMO, respectively) is verified by the appearance of a broad band at $3380 \mathrm{~cm}^{-1}$, characteristic of the $\mathrm{O}-\mathrm{H}$ stretch of alcohols (Figure 1), in addition to the disappearance of the peaks at $1650 \mathrm{~cm}^{-1}$ and $3009 \mathrm{~cm}^{-1}$, which are related to unsaturations of the fatty acid chains [3].

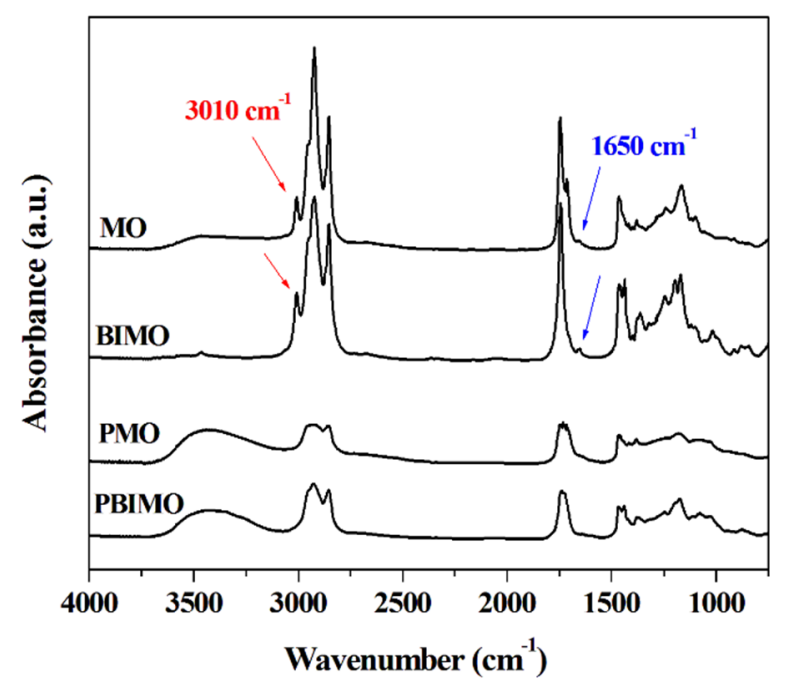

Figure 1. FTIR spectra of macauba oil (MO), polyol from macauba oil (PMO), macauba oil methyl esters (BIMO), and polyol from macauba oil methyl esters (PBIMO).

The successful conversion of PMO and PBIMO into PUs with varying $[\mathrm{NCO}] /[\mathrm{OH}]$ molar ratios was also verified by FTIR spectroscopy (Figure S1). The FTIR spectra of all PUMO and PUBIMO samples prepared exhibit bands at approximately $3300 \mathrm{~cm}^{-1}$ and $1530 \mathrm{~cm}^{-1}$, corresponding to $\mathrm{N}-\mathrm{H}$ stretching, and deformation of urethane groups, respectively [33], in addition to bands at 1084-1064 $\mathrm{cm}^{-1}$, assigned to $\mathrm{N}-\mathrm{C}(\mathrm{O})-\mathrm{O}$ deformations. The band at $3300 \mathrm{~cm}^{-1}$ related to the $\mathrm{N}-\mathrm{H}$ stretching can be ascribed to the absorption associated to $\mathrm{N}-\mathrm{H}$ participating in hydrogen bonding as proton donor, which is expected in the hard segments of polyurethanes [34]. The band at $2273 \mathrm{~cm}^{-1}$ is associated with the vibration of free isocyanate groups $(-\mathrm{N}=\mathrm{C}=\mathrm{O})$. The presence of this band confirmed that not all of the isocyanate groups were involved in the condensation polymerization during the PU cure [35]. In the $1750-1700 \mathrm{~cm}^{-1}$ band, there were two overlapping bands; one dominant peak at approximately $1740 \mathrm{~cm}^{-1}$ corresponding to "free" $\mathrm{C}=\mathrm{O}$, and one broad shoulder at approximately $1710 \mathrm{~cm}^{-1}$, corresponding to a $\mathrm{C}=\mathrm{O}$ electron donor stretching associated to inter-urethane hydrogen-bonding [34,36]. The bands at $900-675 \mathrm{~cm}^{-1}$ correspond to vibrations of axial deformation characteristic of the angular deformation outside of the plane of the $\mathrm{C}-\mathrm{H}$ bond of aromatic rings [35,37,38], reminiscent of the MDI structure and clearly shown in the spectrum in Figure $\mathrm{S} 2$. 
Figures 2 and 3 present the FTIR spectra of coconut husk fiber composites prepared from the PUMO and PUBIMO samples. It can be observed that the composites have very similar absorption bands to those of the unreinforced PUs (Figure S1). The major components of ligno-cellulosic materials are cellulose, hemicellulose, and lignin. The major absorption bands observed in these components are regarded to $\mathrm{O}-\mathrm{H}$ stretching $\left(3400-3200 \mathrm{~cm}^{-1}\right), \mathrm{C}=\mathrm{O}$ stretching $\left(1776-1715 \mathrm{~cm}^{-1}\right), \mathrm{C}-\mathrm{O}-\mathrm{C}\left(1270 \mathrm{~cm}^{-1}\right)$ and $\mathrm{C}-\mathrm{OH}\left(\sim 1050 \mathrm{~cm}^{-1}\right)$ deformations. The most intense band attributed to $\mathrm{O}-\mathrm{H}$ and $\mathrm{C}-\mathrm{O}-\mathrm{C}$ is found in cellulose and lignin. Other peaks, due to hydroxyl groups of cellulose, appear at $1360 \mathrm{~cm}^{-1}$ and $1320 \mathrm{~cm}^{-1}[39,40]$. It has been proposed that chemical interactions between the fibers and the PUs matrix can potentially occur through bonds between hydroxyl groups of cellulose and carbonyl groups of the PU, and they are responsible for increasing the interfacial adhesion between filler and matrix $[35,41]$. The shift of the band at approximately $3300 \mathrm{~cm}^{-1}$ for values above $3400 \mathrm{~cm}^{-1}$ suggests the disruption of a significant amount of hydrogen bonds, resulting in a band for "free" $\mathrm{N}-\mathrm{H}$ stretching [34]. However, $\mathrm{C}=\mathrm{O}$ stretching is still observed on the two overlapping bands, in the $1750-1700 \mathrm{~cm}^{-1}$ range $[34,36]$, which can be explained by the substitution of the urethane $\mathrm{NH}$ with $\mathrm{OH}$ from cellulose. The remaining isocyanate band at $2273 \mathrm{~cm}^{-1}$ on the FTIR of the composites (Figures 2 and 3) suggests that there is little interaction between "free" isocyanate groups in PU and hydroxyl groups present in the cellulose of coconut husk fibers [35]. However, the remaining isocyanate band at $2273 \mathrm{~cm}^{-1}$ on the FTIR of the composites (Figures 2 and 3) suggests that there is little interaction between isocyanate groups in PU and hydroxyl groups present in the cellulose of coconut husk fibers [35]. As will be discussed later in the text, non-favorable reinforcement-matrix interactions have also been detected by SEM. This observation is not completely unexpected since cellulose fibers exhibit an intricate structure with nanofibrils tightly connected through hydrogen bonding. Hence, the availability of hydroxyl groups from the fibers to react with isocyanate groups is very limited.

Figure 4 presents TG and DTG curves for MO, PMO, BIMO and PBIMO samples. The TG curve of MO exhibits two stages of thermal decomposition, with $T_{\text {onset }}$ at approximately $268^{\circ} \mathrm{C}$ and discrete mass loss $(17 \%)$, indicating the start of oxidation of fatty acids present in the oil. The second degradation step occurs with $T_{\text {onset }}$ at $396{ }^{\circ} \mathrm{C}$ and can be associated with the cleavage of carbon-carbon bonds along the fatty acid chains. These two steps are associated with heat release $\left(\Delta H=-309 \mathrm{~J} \cdot \mathrm{g}^{-1}\right)$, as determined by DTA (Table 1). PMO also exhibits two stages of thermal decomposition (Figure 4). The first stage exhibits a small endothermic event near $106{ }^{\circ} \mathrm{C}\left(\Delta H=188 \mathrm{~J} \cdot \mathrm{g}^{-1}\right.$, Table 1$)$, possibly due to the cleavage of hydrogen bonds present in the polyol, along with the release of water, which explains the lower $T_{\text {onset. }}$ A pronounced second decomposition step, similar to the second degradation step of MO, can be observed for PMO (Figure 4 and Table 1), which suggests decomposition of the functionalized fatty acid chains. The higher thermal stability observed for MO in comparison to PMO can be directly correlated to their chemical structure. As a matter of fact, $\mathrm{C}=\mathrm{C}\left(614.2 \mathrm{~kJ} \cdot \mathrm{mol}^{-1}\right)$ and $\mathrm{C}-\mathrm{H}\left(413.4 \mathrm{~kJ} \cdot \mathrm{mol}^{-1}\right)$ bonds predominate in $\mathrm{MO}$, while most of the $\mathrm{C}=\mathrm{C}$ bonds are replaced with $\mathrm{C}-\mathrm{OH}$ bonds $\left(353.5 \mathrm{~kJ} \cdot \mathrm{mol}^{-1}\right)$ in PMO, leading to an overall lower thermal stability [3,42]. 


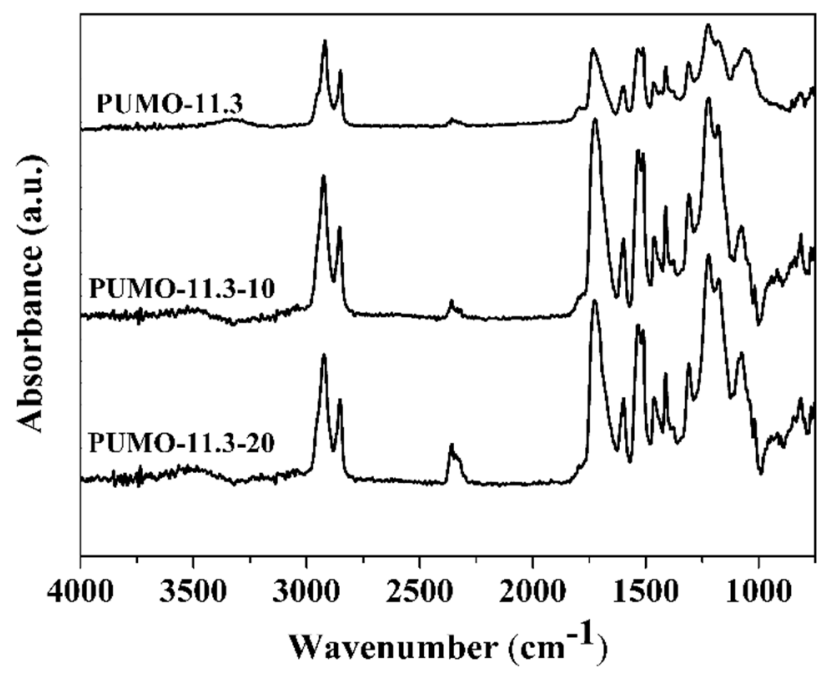

Figure 2. FTIR spectra of PUMO-11.3, PUMO-11.3-10, and PUMO-11.3-20.

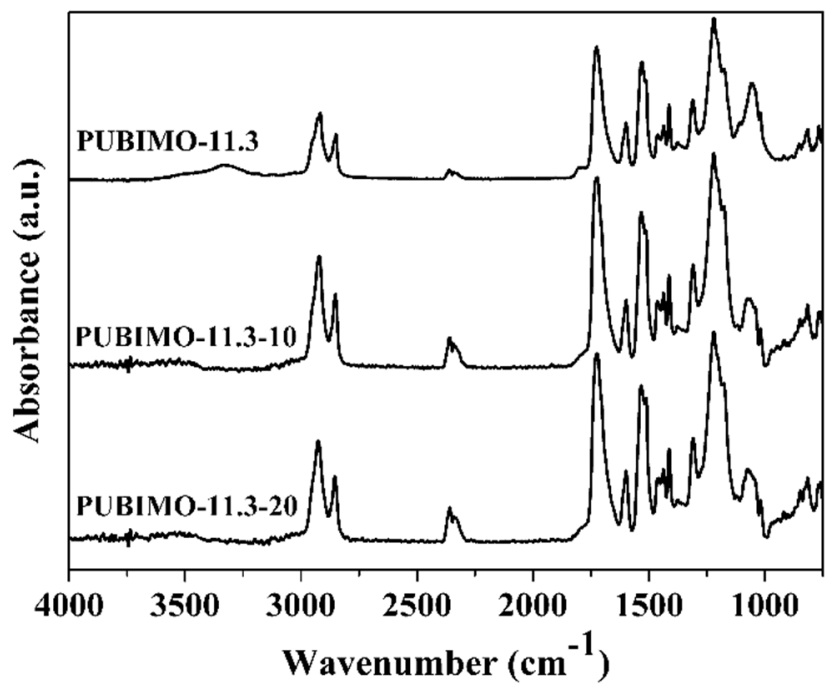

Figure 3. FTIR spectra of PUBIMO-11.3, PUBIMO-11.3-10, and PUBIMO-11.3-20.

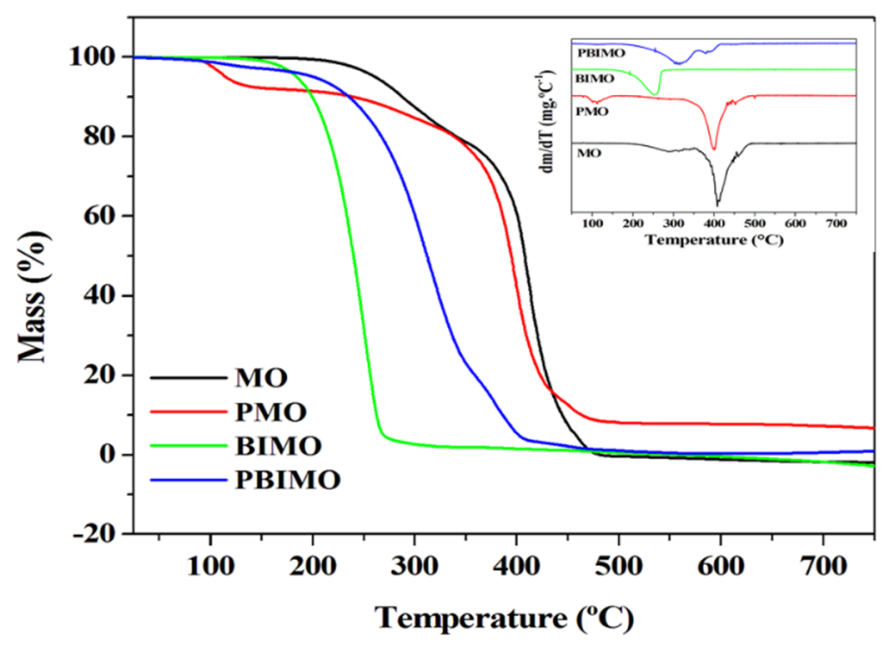

Figure 4. TG and DTG curves of $\mathrm{MO}, \mathrm{PMO}, \mathrm{BIMO}$, and $\mathrm{PBIMO}$, acquired at a heating rate of $10^{\circ} \mathrm{C} \cdot \mathrm{min}^{-1}$. 
Table 1. $T_{\text {onset, }} T_{\mathrm{d}}, \Delta H$ and mass loss of MO, PMO, BIMO and PBIMO.

\begin{tabular}{ccccc}
\hline Material & $\boldsymbol{T}_{\text {onset }}\left({ }^{\circ} \mathbf{C}\right)$ & $\boldsymbol{T}_{\mathbf{d}}\left({ }^{\circ} \mathbf{C}\right)^{\mathbf{a}}$ & $\boldsymbol{\Delta H}\left(\mathbf{J} \cdot \mathbf{g}^{-\mathbf{1}}\right)$ & Mass Loss (\%) \\
\hline \multirow{2}{*}{ MO } & 268 & 289 & -309 & 17 \\
& 396 & 408 & - & 84 \\
PMO & 106 & 112 & $188 ;-294$ & 8 \\
& 368 & 401 & - & 83 \\
BIMO & 233 & 253 & $359 ;-791$ & 98 \\
PBIMO & 288 & 315 & $423 ;-412$ & 99 \\
\hline \multicolumn{5}{c}{}
\end{tabular}

BIMO and PBIMO started their thermal decomposition at $233{ }^{\circ} \mathrm{C}$ and $288{ }^{\circ} \mathrm{C}$, with temperatures of maximum degradation rate $\left(T_{\mathrm{ds}}\right)$ at $253^{\circ} \mathrm{C}$ and $315^{\circ} \mathrm{C}$, respectively (Figure 4 and Table 1$)$. The single degradation stage is associated with decomposition of the methyl esters with formiate/hydroxyl and epoxy groups. In this decomposition, an endothermic process $\left(\Delta H=359 \mathrm{~J} \cdot \mathrm{g}^{-1}\right)$ occurs followed by an exothermic $\left(\Delta H=-791 \mathrm{~J} \cdot \mathrm{g}^{-1}\right)$ (Table 1$)$. PBIMO is more thermally stable than BIMO according to the data on Table 1, suggesting that the thermal degradation mechanisms of these materials are distinct. The increase in thermal stability of PBIMO is confirmed by the greater amount of heat involved in its endothermic process $\left(\Delta H=423 \mathrm{~J} \cdot \mathrm{g}^{-1}\right)$ when compared to BIMO $\left(\Delta H=359 \mathrm{~J} \cdot \mathrm{g}^{-1}\right)$. However, in the exothermic event of PBIMO, the heat release $\left(\Delta H=-412 \mathrm{~J} \cdot \mathrm{g}^{-1}\right)$ is lower than for BIMO $\left(\Delta H=-791 \mathrm{~J} \cdot \mathrm{g}^{-1}\right.$, Table 1). BIMO is less thermally stable than MO due to its lower molecular weight. However, the epoxidation/hydroxylation reaction of BIMO to produce PBIMO results in an increased thermal stability due to the formation of hydrogen bonds in the polyol. The $\Delta H$ values corresponding to the decomposition processes of PUs and composites (not shown) are not very defined, and therefore don't provide relevant information about the materials prepared.

Figure 5 shows the TG curves for PUMO and PUBIMO in $[\mathrm{NCO} / \mathrm{OH}]$ molar ratios of 11.3, 13.6 and 15.1. The profile of these curves suggests that the thermal decomposition occurs in two stages for PUBIMO-13.6 and PUBIMO-15.1, and three stages for PUBIMO-11.3 and all PUMO samples. The first stage of thermal decomposition of PUBIMO-11.3 and all PUMO samples is discrete in comparison to the other two stages. Therefore, the two subsequent stages are considered as the main degradation steps of the PUs prepared in this work. The first main degradation step, related to the thermal decomposition of urethane bonds, was more pronounced than the second main degradation step, related to the formation of primary and secondary amines. According to the data presented in Table 2, PUBIMO-13.6 and PUBIMO-15.1 are more thermally stable than PUMO in the same molar ratios. Overall, no coherent trends in the thermal stability of PUs are observed with variations in the $[\mathrm{NCO}] /[\mathrm{OH}]$ molar ratios.

Figure 6a displays TG and DTG curves of PUMO-11.3 and its composites with $10 \mathrm{wt} \%$ and $20 \mathrm{wt} \%$ coconut husk fibers (PUMO-11.3-10 and PUMO-11.3-20, respectively). Table 2 collects the respective degradation temperatures and mass losses. Both data reveal that PUMO-11.3-20 is thermally more stable than PUMO-11.3-10. Indeed, an increase in thermal stability is expected upon reinforcement of PUs with coconut husk fibers, especially in the first decomposition stage. The decomposition of the composites occurs in two stages. The first stage, with $T_{\mathrm{ds}} 363^{\circ} \mathrm{C}$ and $393{ }^{\circ} \mathrm{C}$ for PUMO-11.3-10 and PUMO-11.3-20, respectively, corresponds to the decomposition of urethane groups in the $\mathrm{PU}$, and cellulose and hemicellulose 
from the fibers [35]. The second decomposition step, with $T_{\mathrm{d}} \sim 460^{\circ} \mathrm{C}$ for the two composites, corresponds to the structural degradation of the fatty acid chains and lignin [43].

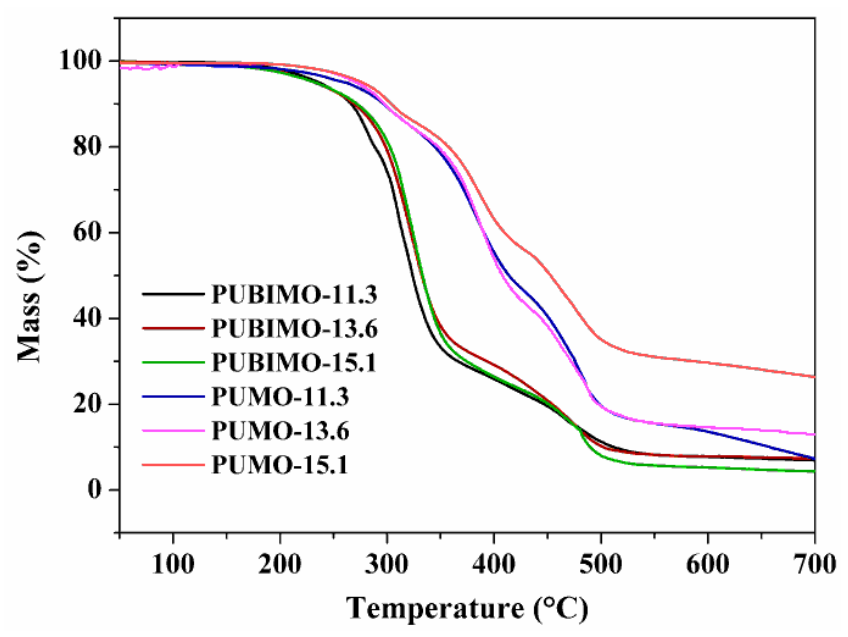

Figure 5. TG curves of PUBIMO-11.3, PUBIMO-13.6, PUBIMO-15.1, PUMO-11.3, PUMO-13.6, and PUMO-15.1, acquired at a heating rate of $10^{\circ} \mathrm{C} \cdot \mathrm{min}^{-1}$.

Table 2. $T_{\text {onset, }} T_{\mathrm{d}}$, and mass loss of PUMO and PUBIMO in $[\mathrm{NCO} / \mathrm{OH}]$ molar ratios of 11.3, 13.6, and 15.1; PUMO-11.3 and PUBIMO-11.3 with $10 \mathrm{wt} \%$ and $20 \mathrm{wt} \%$ of coconut husk fibers.

\begin{tabular}{|c|c|c|c|}
\hline Material & $T_{\text {onset }}\left({ }^{\circ} \mathrm{C}\right)$ & $T_{\mathrm{d}}\left({ }^{\circ} \mathrm{C}\right)^{\mathrm{a}}$ & Mass Loss (\%) \\
\hline \multirow{2}{*}{ PUMO-11.3 } & 322 & 381 & 50 \\
\hline & 469 & 484 & 33 \\
\hline \multirow{2}{*}{ PUMO-11.3-10 } & 311 & 363 & 40 \\
\hline & 449 & 462 & 58 \\
\hline \multirow{2}{*}{ PUMO-11.3-20 } & 324 & 393 & 53 \\
\hline & 444 & 459 & 35 \\
\hline \multirow{2}{*}{ PUMO-13.6 } & 277 & 299 & 17 \\
\hline & 363 & 390 & 74 \\
\hline \multirow{3}{*}{ PUMO-15.1 } & 279 & 303 & 13 \\
\hline & 363 & 384 & 27 \\
\hline & 496 & 477 & 30 \\
\hline \multirow{2}{*}{ PUBIMO-11.3 } & 269 & 303 & 61 \\
\hline & 536 & 603 & 29 \\
\hline \multirow{2}{*}{ PUBIMO-11.3-10 } & 323 & 328 & 67 \\
\hline & 464 & 469 & 21 \\
\hline \multirow{2}{*}{ PUBIMO-11.3-20 } & 280 & 327 & 59 \\
\hline & 408 & 469 & 19 \\
\hline \multirow{2}{*}{ PUBIMO-13.6 } & 296 & 319 & 68 \\
\hline & 440 & 478 & 23 \\
\hline \multirow{2}{*}{ PUBIMO-15.1 } & 308 & 326 & 71 \\
\hline & 476 & 481 & 21 \\
\hline
\end{tabular}

${ }^{\text {a }} T_{\mathrm{d}}=$ temperature of maximum degradation rate. 

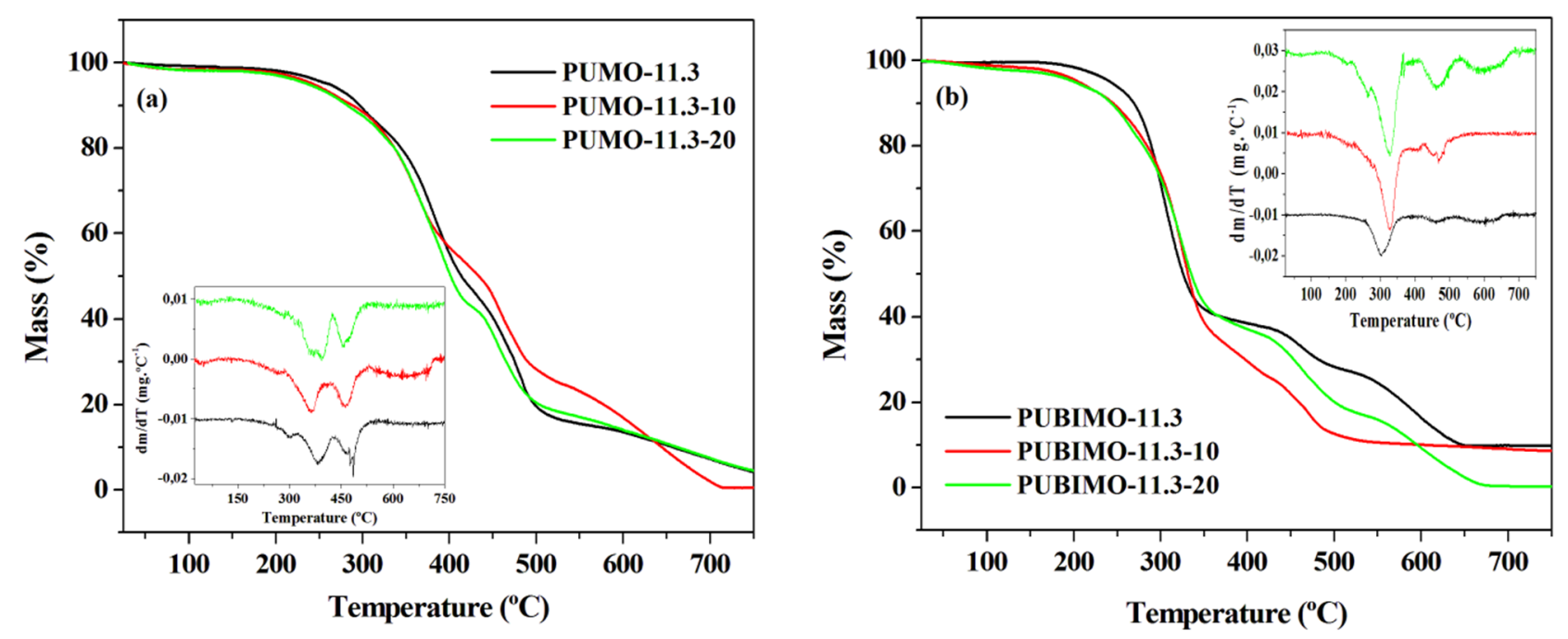

Figure 6. TG and DTG curves of: (a) PUMO-11.3, PUMO-11.3-10, and PUMO-11.3-20; (b) PUBIMO-11.3, PUBIMO-11.3-10, and PUBIMO-11.3-20, acquired at a heating rate of $10^{\circ} \mathrm{C} \cdot \mathrm{min}^{-1}$.

A comparison of the TG and DTG curves of PUBIMO-11.3, PUBIMO-11.3-10, and PUBIMO-11.3-20 are presented in Figure $6 \mathrm{~b}$. While three stages of thermal decomposition are observed for PUBIMO-11.3 and PUBIMO-11.3-20, only two degradation steps are observed for PUBIMO-11.3-10. Both composites exhibit $T_{\mathrm{d}} \sim 328{ }^{\circ} \mathrm{C}$ for the first stage and $T_{\mathrm{d}} \sim 469{ }^{\circ} \mathrm{C}$ for the second stage. Furthermore, a comparison of the DTG curves of the composites reveals that $T_{\text {onset }}$ (Table 2) at each peak does not change significantly, indicating that the addition of fibers did not alter the thermal stability of the materials on a measurable level, possibly because of limited interactions between the polymer matrix and the coconut husk fibers.

Mechanical properties of PUs from MO, and their corresponding composites, were obtained through DMA. The results are shown in Table 3. It is worth noting that even though PUs and composites from BIMO have been successfully prepared, they consistently broke during the initial cooling of the DMA testing, making the acquisition of mechanical data for these samples impossible.

Table 3. DMA results for PUs from MO and their corresponding composites.

\begin{tabular}{ccccc}
\hline Entry & Sample & $\boldsymbol{T}_{\mathbf{g}}\left({ }^{\circ} \mathbf{C}\right)$ & $\boldsymbol{E}^{\prime}$ at $25{ }^{\circ} \mathbf{C}(\mathbf{M P a})$ & ${\text { Extractables }(\mathbf{w t} \%)^{\mathbf{a}}}$ \\
\hline 1 & PUMO-11.3 & 68 & 20.1 & 21 \\
2 & PUMO-13.6 & 76 & 12.2 & 16 \\
3 & PUMO-15.1 & 106 & 16.1 & 11 \\
4 & PUMO-11.3-10 & $-14 ; 55$ & 33.4 & - \\
5 & PUMO-11.3-20 & $-2 ; 53$ & 24.8 & - \\
\hline
\end{tabular}

${ }^{\text {a }}$ Results obtained after Soxhlet extraction for $24 \mathrm{~h}$ with methylene chloride.

The role played by the $[\mathrm{NCO}] /[\mathrm{OH}]$ molar ratio on the $T_{\mathrm{g}}$ of PUs can be clearly seen in Table 3 (entries 1-3). As mentioned previously, an increase in the crosslink density of the PU is expected with an increase in the $[\mathrm{NCO}] /[\mathrm{OH}]$ molar ratio. The increase in crosslink density with $[\mathrm{NCO}] /[\mathrm{OH}]$ molar ratio can be indirectly estimated from the percentage of extractable materials (non-crosslinked) obtained 
after Soxhlet extraction of the PUs with methylene chloride for $24 \mathrm{~h}$ (Table 3, entries 1-3). It can be clearly seen in Table 3 that the percentage of extractable materials decreases as the $[\mathrm{NCO}] /[\mathrm{OH}]$ molar ratio increases. Such an increase in crosslink density also translates into an increase of the $T_{\mathrm{g}}$. Nevertheless, the increase in $T_{\mathrm{g}}$ is not accompanied by a consistent change in the storage modulus $\left(E^{\prime}\right)$ at $25{ }^{\circ} \mathrm{C}$. A significant excess of [NCO] with respect to $[\mathrm{OH}]$ had to be employed during PU synthesis due to the low functionality of $\mathrm{MO}$, and imposes a limiting factor for $[\mathrm{NCO}] /[\mathrm{OH}]$ molar ratio variations from a practical standpoint. Due to the fact that the $[\mathrm{NCO}] /[\mathrm{OH}]$ molar ratio variations herein are not strikingly large, and due to unavoidable sample heterogeneity, it is possible that the proposed trend in crosslink density is not reflected in $E^{\prime}$. As a matter of fact, although significant, the change in $E^{\prime}$ with $[\mathrm{NCO}] /[\mathrm{OH}]$ molar ratio is fairly small, compared to the improvement seen when PUMO-13.1 is reinforced with coconut husk fibers (entries 1, 4, and 5, Table 3).

Another interesting observation from the reinforcement of PUs with coconut husk fibers is the appearance of two $T_{\mathrm{gs}}$, which indicates a clear interference of the fibers with the condensation polymerization reaction. Similar effects have also been observed during the free radical polymerization of conjugated linseed oil in the presence of rice hulls, and have been attributed to the dispersion of co-monomers during the cure of the composite [44]. Similar to the change in $[\mathrm{NCO}] /[\mathrm{OH}]$ molar ratios, an increase in filler load from $10 \mathrm{wt} \%$ to $20 \mathrm{wt} \%$ does not result in the expected increase in storage modulus. An uneven dispersion of the fibers throughout the composites may have led to such results. The dispersion of the fibers will be discussed later in the text. The foam aspect of the PUs and the size of the molds used made it impossible to conduct tensile tests. However, one can appreciate the reinforcing effect of coconut husk fibers when comparing the storage modulus of PUMO-11.3, PUMO-11.3-10, and PUMO-11.3-20 (Table 3, entries 1, 4, and 5), as mentioned previously. Indeed, a minimum improvement of approximately $23 \%$ in $E^{\prime}$ at $25{ }^{\circ} \mathrm{C}$ is obtained when incorporating coconut husk fibers in the PU matrix.

The effect of adding coconut husk fibers to PUMO-13.1 can be better visualized in Figure 7, which presents a comparison of the DMA results for the PU with and without the reinforcement. In addition to the already mentioned increase in $E^{\prime}$ at $25{ }^{\circ} \mathrm{C}$ and the appearance of two $T_{\mathrm{gs}}$ with the addition of the fibers, it can be seen that the unreinforced sample broke prematurely $\left(\sim 120^{\circ} \mathrm{C}\right.$, Figure 7$)$, whereas the composite endured the full temperature range tested $\left(-60-200^{\circ} \mathrm{C}\right)$. Such behavior shows that the fibers have a positive impact on the ability of the material in supporting the repetitive stress imposed during the DMA test. Figure 7 also shows an inversion in the expected trend for $E^{\prime}$ between 40 and $70{ }^{\circ} \mathrm{C}$, which reflects the lower $T_{\mathrm{gs}}$ observed for the composite in comparison to the unreinforced PU. As discussed previously, it is likely that the presence of the fibers during curing of the PU interferes with the condensation polymerization of the resin components, resulting in the unexpected trend in $E^{\prime}$ and $T_{\mathrm{g}}$.

SEM was used to assess morphological features of different PUs and composites. Figure 8 presents a visual comparison of select images obtained in this study. Overall, the images show poor fiber-matrix interaction, varying pore size distribution, and fracture features of flexible materials. 


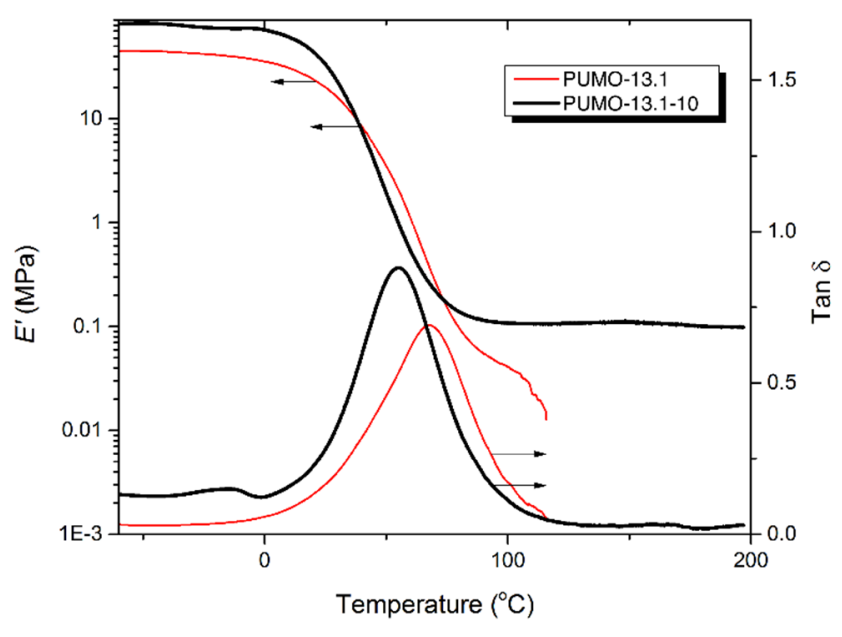

Figure 7. DMA results for PUMO-13.1 e PUMO-13.1-10.

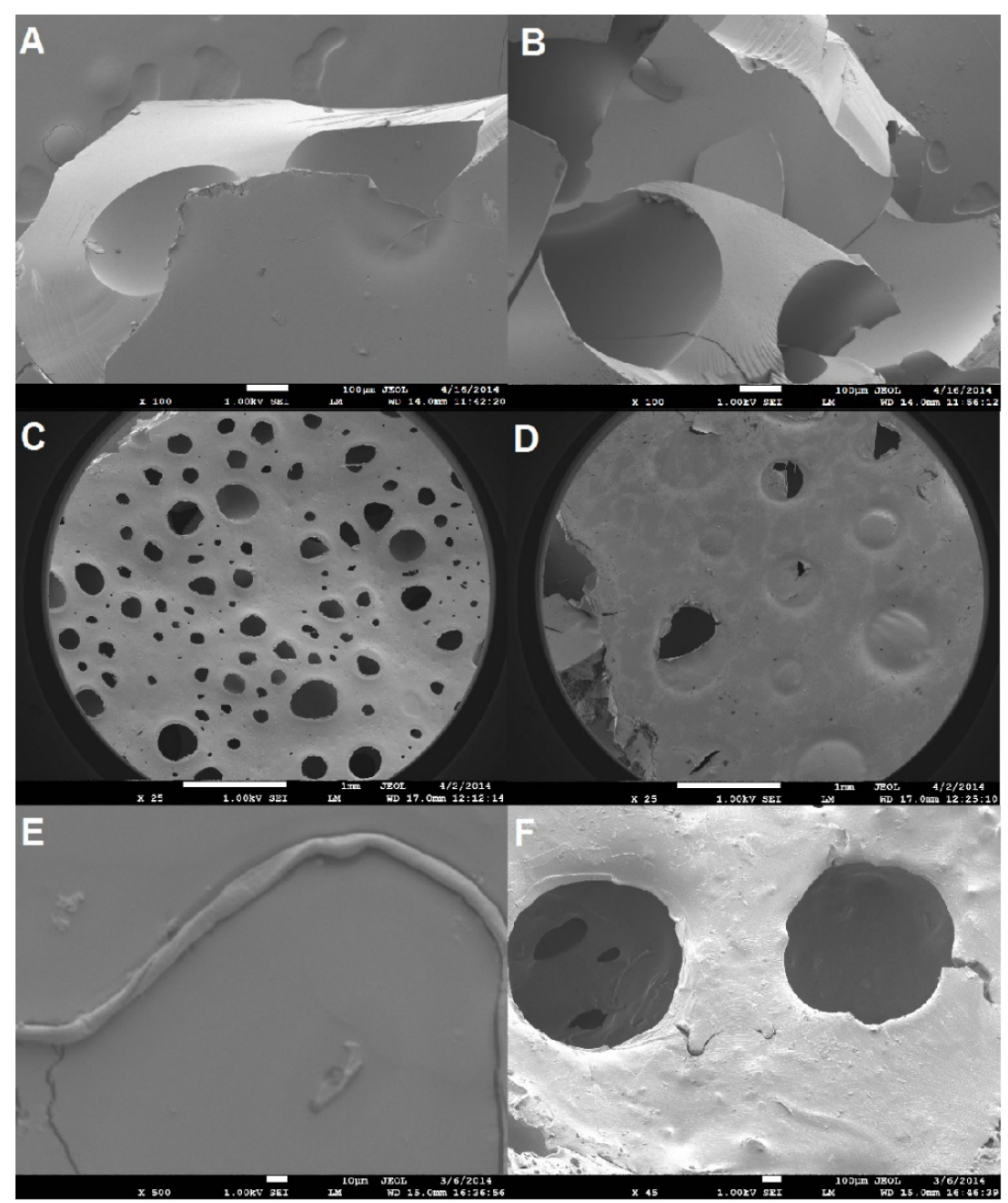

Figure 8. SEM images of (A) cryo-fracture surface of PUBIMO-15.1 at $100 \times$ (the scale bar corresponds to $100 \mu \mathrm{m}$ ); (B) cryo-fracture surface of PUBIMO-13.6 at 100× (the scale bar corresponds to $100 \mu \mathrm{m}$ ); (C) PUMO-11.3 at $25 \times$ (the scale bar corresponds to $1 \mathrm{~mm}$ ); (D) PUBIMO-15.1 at $25 \times$ (the scale bar corresponds to $1 \mathrm{~mm}$ ); (E) PUBIMO-11.3-20 at $500 \times$ (the scale bar corresponds to $10 \mu \mathrm{m}$ ); and (F) PUBIMO-11.3-20 at $45 \times$ (the scale bar corresponds to $100 \mu \mathrm{m})$. 
Figure 8A,B shows the top fractured edge view of PUBIMO-15.1 and PUBIMO-13.6, respectively. A comparison of the fractured surfaces in both samples indicates minimum morphological difference when the $[\mathrm{NCO}] /[\mathrm{OH}]$ molar ratio is varied. The crease lines observed on either image portray the semi-flexible nature of the PUs made from BIMO polyols. As a result of the residual water detected in the polyol from MO, as described when discussing the TG results, PUs made from triglycerides exhibit a significantly increased number of cells when compared to PUs made from BIMO polyols. This trend can be clearly seen in Figure 8C,D, which depicts PUMO-11.3 and PUBIMO-15.1, respectively. Figure 8E displays the poor interaction between the coconut fiber and the matrix in PUBIMO-11.3-20. No PU artifacts are found on the fibers identified in the composite samples analyzed. Despite the potential condensation between isocyanate groups and the ligno-cellulosic fibers during the synthesis of the composites, it is hypothesized that the PU network formed is highly hydrophobic due to the long fatty acid chains and low functionality in MO, contrasting with the hydrophilic nature of the coconut husk fibers used as reinforcement. In Figure $8 \mathrm{~F}$, a satisfactory horizontal fiber distribution can be observed throughout the composite with only a few visible fibers sparsely distributed. The low number of fibers identified suggests an uneven vertical fiber distribution. Indeed, settling of the fibers may have occurred during the final cure of the composites, which could explain some of the trends obtained in the DMA tests of the composites. Figure 9 shows the bottom view of the composite shown in Figure $8 \mathrm{~F}$ at the same magnification. A comparison of Figures 8F and 9 reveals the aforementioned uneven vertical fiber distribution. Indeed, a higher number of fibers can be visualized throughout the matrix in Figure 9 in comparison to Figure 8F. In Figure 9, the horizontal distribution is comparable to that observed in Figure $8 \mathrm{~F}$, with an overall satisfactory distribution of unbundled, interspaced fibers.

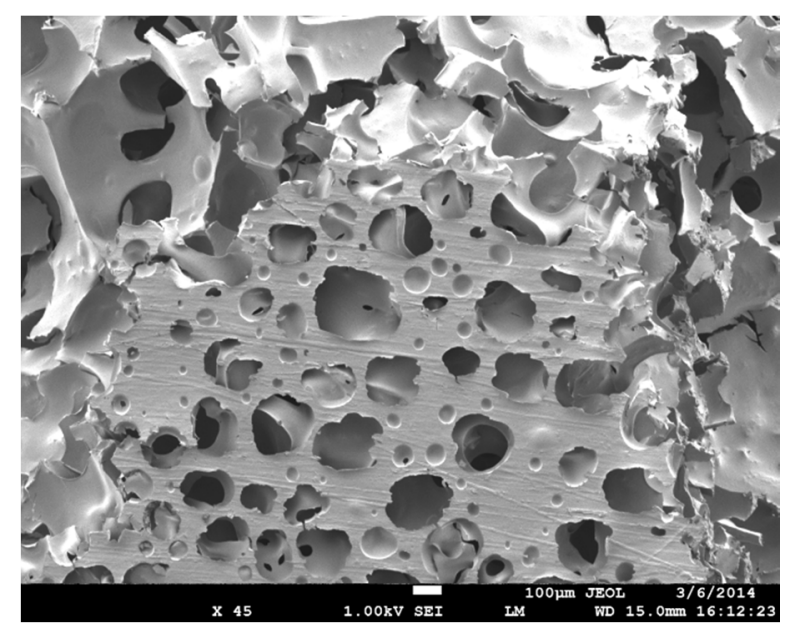

Figure 9. Scanning electron micrograph of the bottom view of PUBIMO-11.3-20 at $45 \times($ the scale bar corresponds to $100 \mu \mathrm{m})$.

\section{Conclusions}

The use of macauba oil as a starting material for the synthesis of polyols and polyurethanes is extremely viable. Despite the lower content of hydroxyl groups, the polyol synthesized from macauba oil is still capable of react with isocyanate to produce polyurethane materials. The thermal stability of these polyurethanes can be slightly tuned by varying the $[\mathrm{NCO}] /[\mathrm{OH}]$ molar ratio. In comparison to 
other systems, prepared from oils such as linseed and passion fruit oils $[3],[\mathrm{NCO}] /[\mathrm{OH}]$ molar ratios approximately ten times higher had to be employed in order to obtain viable materials with higher $T_{\mathrm{gs}}$. Indeed, the MO-based PUs reported here exhibit $T_{\mathrm{gs}}$ ranging from 68 to $106{ }^{\circ} \mathrm{C}$, whereas PUs from linseed and passion fruit oils exhibit $T_{\mathrm{gs}}$ of $42{ }^{\circ} \mathrm{C}$ and $31{ }^{\circ} \mathrm{C}$, respectively [3]. Moreover, the addition of coconut husk fibers improves the mechanical properties of the polyurethane matrix, even though the chemical interaction of both components is limited. Despite its simplicity, the current approach results in biocomposites with thermal and mechanical properties that cannot go unnoticed. For example, PUMO-11.3 displayed $T_{\mathrm{g}}$ and $E^{\prime}$ at $25{ }^{\circ} \mathrm{C}$ of $68{ }^{\circ} \mathrm{C}$ and $20.1 \mathrm{MPa}$, respectively. The introduction of coconut husk fibers changed these values to $55^{\circ} \mathrm{C}$ and $33.4 \mathrm{MPa}$, respectively. If one considers the storage modulus alone, the increase is approximately $56 \%$, which is comparable to the $60 \%$ increase that cellulose nano-crystals provided to green polyethylene as reported elsewhere [22]. Moreover, the bio-based PU matrix, as well as the coconut husk fiber, is prone to undergo chemical modifications and also show miscibility with vegetable oils. These features will permit one to improve the properties of these composites even further. Therefore, the route proposed herein is cost-effective, relatively simple, reproducible, and successfully produces environmentally-friendly materials for structural applications.

\section{Acknowledgements}

The authors thank Júlio L. de Macedo for the help with the transesterification of MO, the Brazilian National Council of Technological and Scientific Development (CNPq), the Institute of Chemistry at the University of Brasilia (IQ/UnB), and the College of Science and Mathematics, and the Chemistry Department at Georgia Southern University for the financial support.

\section{Author Contributions}

Maria José A. Sales conceived and designed the experiments; Taynara F. da Silva and Amanda Payne performed the experiments; Rafael L. Quirino, Roseany de V. V. Lopes, and Leonardo G. Paterno analyzed the data; Maria José A. Sales contributed reagents/materials/analysis tools; Rafael L. Quirino wrote the paper.

\section{Conflicts of Interest}

The authors declare no conflict of interest.

\section{References}

1. Datta, J.; Glowinska, E. Chemical modifications of natural oils and examples of their usage for polyurethane synthesis. J. Elastom. Plastics 2014, 46, 33-42.

2. Firdaus, F.E. The selection reaction of homogeneous catalyst in soy-epoxide hydroxylation. J. Physics Conf. Series 2014, 495, 1-8.

3. Lopes, R.V.V.; Loureiro, N.P.D.; Pezzin, A.P.T.; Gomes, A.C.M.; Resck, I.S.; Sales, M.J.A. Synthesis of polyols and polyurethanes from vegetable oils-kinetic and characterization. J. Polym. Res. 2013, 20, 1-9. 
4. Kong, X.; Liu, G.; Qi, H.; Curtis, J.M. Preparation and characterization of high-solid polyurethane coating systems based on vegetable oil derived polyols. Prog. Org. Coat. 2013, 76, 1151-1160.

5. Mosiewick, M.A.; Aranguren, M.I. A short review on novel biocomposites based on plant oil precursors. Europ. Polym. J. 2013, 49, 1243-1256.

6. Jang, J.Y.; Jeong, T.K.; Oh, W.J.; Youn, J.R.; Song, Y.S. Thermal stability and flammability of coconut fiber reinforced poly(lactic acid) composites. Composites B 2012, 43, 2434-2438.

7. Lomelí-Ramírez, M.G.; Kestur, S.G.; Manríquez-González, R.; Iwakiri, S.; Muniz, G.B.; Flores-Sahagun, T.S. Bio-composites of cassava starch-green coconut fiber: Part II-Structure and properties. Carbohydr. Polym. 2014, 102, 576-583.

8. Thanh, L.T.; Okitsu, K.; Maeda, Y.; Bandow, H. Ultrasound assisted production of fatty acid methyl esters from transesterification of triglycerides with methanol in the presence of $\mathrm{KOH}$ catalyst: Optimization, mechanism and kinetics. Ultrason. Sonochem. 2014, 21, 467-471.

9. Mirtschin, N.; Pretsch, T. Designing temperature-memory effects in semicrystalline polyurethane. RSC Adv. 2015, 5, 46307-46315.

10. Bothe, M.; Pretsch, T. Bidirectional actuation of a thermoplastic polyurethane elastomer. J. Mater. Chem. A 2013, 1, 14491-14497.

11. Bothe, M.; Emmerling, F.; Pretsch, T. Poly(ester urethane) with varying polyester chain length: Polymorphism and shape-memory behavior. Macromol. Chem. Phys. 2013, 214, 2683-2693.

12. Waletzko, R.S.; Korley, L.T.J.; Pate, B.D.; Thomas, E.L.; Hammond, P.T. Role of increased crystallinity in deformation-induced structure of segmented thermoplastic polyurethane elastomers with PEO and PEO-PPO-PEO soft segments and HDI hard segments. Macromolecules 2009, 42, 2041-2053.

13. Li, F.; Hou, J.; Zhu, W.; Zhang, X.; Xu, M.; Luo, X.; Ma, D.; Kim, B.K. Crystallinity and morphology of segmented polyurethanes with different soft-segment length. J. Appl. Polym. Sci. 1996, 62, 631-638.

14. Rios, L.; Echeverri, D.; Cardeño, F. Hydroxylation of vegetable oils using acidic resins as catalysts. Ind. Crops Prod. 2013, 43, 183-187.

15. Ciconini, G.; Favaro, S.P.; Roscoe, R.; Miranda, C.H.B.; Tapeti, C.F.; Miyahira, M.A.M.; Bearari, L.; Galvani, F.; Borsato, A.V.; Colnago, L.A.; et al. Biometry and oil contents of Acrocomia aculeata fruits from the Cerrados and Pantanal biomes in Mato Grosso do Sul, Brazil. Ind. Crops Prod. 2013, $45,208-214$.

16. Coimbra, M.C.; Jorge, N. Characterization of the pulp and kernel oils from Syagrus oleracea, Syagrus romanzoffiana, and Acrocomia aculeate. J. Food Sci. 2011, 76, 1156-1161.

17. Almeida, T.M.; Bispo, M.D.; Cardoso, A.R.T.; Migliorini, M.V.; Schena, T.; Campos, M.C.V.; Machado, M.E.; López, J.A.; Krause, L.C.; Caramão, E.B. Preliminary studies of bio-oil from fast pyrolysis of coconut fibers. J. Ag. Food Chem. 2013, 61, 6812-6821.

18. Rencoret, J.; Ralph, J.; Marques, G.; Gutiérrez, A.; Martínez, A.T.; Río, J.C. Structural characterization of lignin isolated from coconut (Cocos nucifera) coir fibers. J. Ag. Food Chem. 2013, 61, 2434-2445.

19. Rosa, M.F.; Medeiros, E.S.; Malmonge, J.A.; Gregorski, K.S.; Wood, D.F.; Mattoso, L.H.C.; Glenn, G.; Orts, W.J.; Imam, S.H. Cellulose nanowhiskers from coconut husk fibers: Effect of preparation conditions on their thermal and morphological behavior. Carbohydr. Polym. 2010, 81, 83-92. 
20. Wang, C.; Zhang, Y.; Lin, L.; Ding, L.; Li, J.; Lu, R.; He, M.; Xie, H.; Cheng, R. Thermal, mechanical, and morphological properties of functionalized graphene-reinforced bio-based polyurethane nanocomposites. Eur. J. Lipid Sci. Technol. 2015, 117, doi:10.1002/ej1t.201500029.

21. Thakura, S.; Karak, N. Bio-based tough hyperbranched polyurethane-graphene oxide nanocomposites as advanced shape memory materials. RSC Adv. 2013, 3, 9476-9482.

22. Castro, D.O.; Frollini, E.; Ruvolo-Filho, A.; Dufresne, A. "Green polyethylene" and curauá cellulose nanocrystal based nanocomposites: Effect of vegetable oils as coupling agent and processing technique. J. Polym. Sci. B Polym. Phys. 2015, 53, 1010-1019.

23. Mazzon, E.; Habas-Ulloa, A.; Habas, J.-P. Lightweight rigid foams from highly reactive epoxy resins derived from vegetable oil for automotive applications. Eur. Polym. J. 2015, 68, 546-557.

24. Monteavaro, L.L.; Silva, E.O.; Costa, A.P.O.; Samios, D.; Gerbase, A.E.; Petzhold, C.L. Polyurethane networks from formiated soy polyols: Synthesis and mechanical characterization. J. Am. Oil Chem. Soc. 2005, 82, 365-371.

25. ASTM D1957-86 Standard Test Method for Hydroxyl Value of Fatty Oils and Acids; ASTM: West Conshohocken, PA, USA, 1995.

26. ASTM D5155-96 Standard Test Method for Polyurethane Raw Materials-Determination on the Isocyanate Content of Aromatic Isocyanates; ASTM: West Conshohocken, PA, USA, 2005.

27. Melo, M.A.M.F. Avaliação das Propriedades de Óleos Vegetais Visando a Produção de Biodiesel. Master's Thesis, Federal University of Paraíba, Joao Pessoa-PB, Brazil, 2010.

28. Lopes, R.V.V.; Loureiro, N.P.D.; Zamian, J.R.; Fonseca, O.S.; Macedo, J.L.; Santos, M.L.; Sales, M.J.A. Synthesis and characterization of polymeric materials from vegetable oils. Macromol. Symp. 2009, 286, 89-94.

29. Guner, F.S.; Yagci, Y.; Erciyes, A.T. Polymers from triglyceride oils. Prog. Polym. Sci. 2006, 31, 633-670.

30. Lazzari, M.; Chiantore, O. Drying and oxidative degradation of linseed oil. Polym. Degrad. Stability 1999, 65, 303-313.

31. Guzatto, R.; Defferrari, D.; Reiznautt, Q.B.; Cadore, I.R.; Samios, D. Transesterification double step process modification for ethyl ester biodiesel production from vegetable and waste oils. Fuel 2012, 92, 197-203.

32. Yuan, T.; Akochi-Koble, E.; Pinchuk, D.; Van de Voort, F.R. FTIR on-line monitoring of biodiesel transesterification. Int. J. Renew. Energy Biofuels 2014, 2014, 1-13.

33. Narine, S.S.; Kong, X.; Bouzidi, L.; Sporns, P. Physical properties of polyurethanes produced from polyols from seed oils: II. Foams. J. Am. Oil Chem. Soc. 2007, 84, 65-72.

34. Seymour, R.W.; Estes, G.M.; Cooper, S.L. Infrared studies of segmented polyurethan elastomers. I. Hydrogen bonding. Macromolecules 1970, 3, 579-583.

35. Kong, X.; Narine, S.S. Physical properties of polyurethane plastic sheets produced from polyols from canola oil. Biomacromolecules 2007, 8, 2203-2209.

36. Pretsch, T.; Jakob, I.; Müller, W. Hydrolytic degradation and functional stability of a segmented shape memory poly(ester urethane). Polym. Degrad. Stab. 2009, 94, 61-73.

37. Silverstein, R.M.; Webster, F.X. Identificação Espectrométrica de Compostos Orgânicos, 6th ed.; LCT: Rio de Janeiro-RJ, Brazil, 2000. 
38. Merlini, C.; Soldi, V.; Barra, G.M.O. Influence of fiber surface treatment and length on physico-chemical properties of short random banana fiber-reinforced castor oil polyurethane composites. Polym. Test. 2011, 30, 833-840.

39. Sgriccia, N.; Hawley, M.C.; Misra, M. Characterization of natural fiber surface and natural fiber composites. Composites A 2008, 39, 1632-1637.

40. Tomczak, F. Estudos sobre a estrutura e propriedades de fibras de coco e curauá do Brasil. Master's Thesis, Federal University of Paraná, Curitiba-PR, Brazil, 2010.

41. Mothé, C.G.; Araújo, C.R.; Wang, S.H. Thermal and mechanicals characteristics of polyurethane/curaua fiber composites. J. Therm. Anal. Calorim. 2009, 95, 181-185.

42. Vollhardt, K.P.C.; Schore, N.E. Química Orgânica: estrutura e função, 4th ed.; Bookman: Porto Alegre-RS, Brazil, 2004.

43. Idicula, M.; Malhotra, S.K.; Joseph, K.; Thomas, S. Dynamic mechanical analysis of randomly oriented intimately mixed short banana/sisal hybrid fibre reinforced polyester composites. Compos. Sci. Technol. 2005, 65, 1077-1087.

44. Quirino, R.L.; Larock, R.C. Rice hull biocomposites. I. Preparation of a linseed-oil-based resin reinforced with rice hulls. J. Appl. Polym. Sci. 2011, 121, 2039-2049.

(C) 2015 by the authors; licensee MDPI, Basel, Switzerland. This article is an open access article distributed under the terms and conditions of the Creative Commons Attribution license (http://creativecommons.org/licenses/by/4.0/). 